\title{
Transcatheter aortic valve replacement with intracardiac echocardiography from the right internal jugular vein
}

\author{
Hiroto Yagasaki ${ }^{1}$, Yoshiaki Goto ${ }^{1}$, Yoshio Mori ${ }^{2}$, Toshiyuki Noda ${ }^{1}$ \\ ${ }^{1}$ Department of Cardiology, ${ }^{2}$ Department of Cardiovascular Surgery, Gifu Prefectural General Medical Center, Gifu City, Gifu, Japan \\ Correspondence to: Hiroto Yagasaki, MD. Department of Cardiology, Gifu Prefectural General Medical Center, Gifu City, Gifu, Japan. \\ Email: y.pilottio@gmail.com.
}

\begin{abstract}
Transesophageal echocardiography (TEE) is a useful imaging modality to guide transcatheter aortic valve replacement (TAVR). The limitations of TEE include the need for general anesthesia (GA) and endotracheal intubation. In Europe, TAVR under local anesthesia (LA) is usually performed without TEE. An intracardiac echocardiography (ICE) catheter may be used as an alternative to TEE, but the catheter is usually inserted from the femoral vein (FV-ICE). There are some reports of TAVR with FV-ICE; however, there are no reports of ICE inserted from the right internal jugular vein (JV-ICE). In the first case of its kind, we successfully performed TAVR under LA with JV-ICE. JV-ICE allows for the evaluation of perioperative hemodynamics, measurement of the aortic valve complex, and assessment of major complications during the procedure without interference from the operator or fluoroscopes; these represent a distinct advantage over TEE, transthoracic echocardiography, and FV-ICE. Moreover, there is no need for the echocardiologist to use maximal barrier precautions; the catheter can be operated in the standing position, like TEE; and operability is higher than that with FV-ICE. TAVR with JV-ICE is a promising alternative to TAVR under GA with TEE and TAVR under LA with FV-ICE.
\end{abstract}

Keywords: Aortic valve stenosis; valvular disease; transcatheter aortic valve implantation; intracardiac echocardiography (ICE)

Submitted Apr 05, 2018. Accepted for publication Jun 11, 2018.

doi: $10.21037 / \mathrm{cdt} .2018 .07 .06$

View this article at: http://dx.doi.org/10.21037/cdt.2018.07.06

\section{Introduction}

Transcatheter aortic valve replacement (TAVR) is performed for patients who are considered moderate- or high-risk candidates for surgical aortic valve replacement $(1,2)$. Transesophageal echocardiography (TEE) is a useful imaging modality to guide TAVR; however, TEE requires general anesthesia (GA) and endotracheal intubation. In Europe, TAVR is generally performed under local anesthesia (LA) without TEE (3-5). TAVR performed under LA has been shown to be comparable with TAVR performed under GA with respect to patient safety but offers the advantage of shorter hospital stay, ICU days, and procedure time $(6,7)$.

TAVR under GA is usually performed under the guidance of only fluoroscopy, transthoracic echocardiography (TTE), or intracardiac echocardiography (ICE). TEE and TTE probe may interfere with the fluoroscopic image, which makes it difficult to simultaneously evaluate the aortic valve and left ventricle with fluoroscopy. The ICE catheter does not interfere with the fluoroscopic image, so it can display any step of the procedure.

The ICE catheter is usually inserted into the femoral vein $(\mathrm{FV})$ and advanced to the right atrium. There are some reports of TAVR performed under the guidance of an ICE catheter inserted from the FV (FV-ICE) (8-11); however, there are no reports of TAVR performed under the guidance of an ICE catheter inserted from the right internal jugular vein (JV-ICE). During JV-ICE, the echocardiologist can operate without interference from the operator and the sheath of the femoral artery; moreover, the procedure does not require the echocardiologist to be clean. TAVR under 


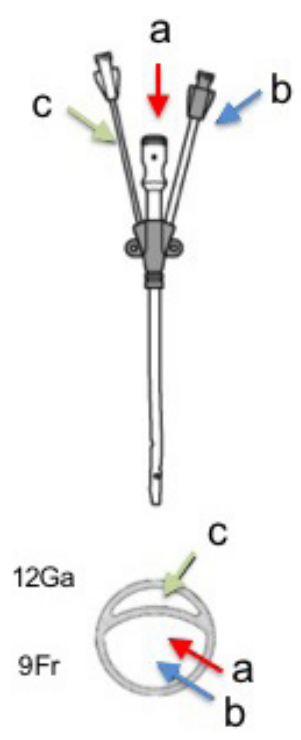

Figure 1 The arrow multilumen access catheter. The lumen a and b together have a diameter of $9 \mathrm{Fr}$, and the lumen c independently have a diameter of $12 \mathrm{Ga}$.

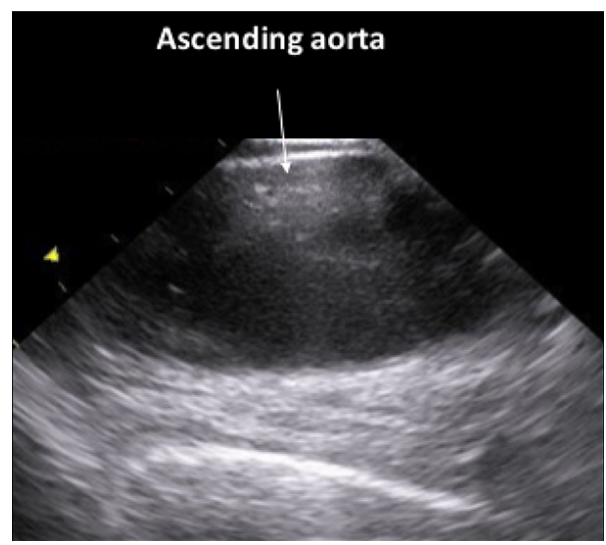

Figure 2 Long-axis ascending aorta view: there was no injury of the ascending aorta.

LA with JV-ICE may be an alternative to TAVR with TEE, TTE, and FV-ICE. We report the first case of TAVR with JV-ICE.

\section{Case presentation}

The patient was an 84-year-old woman with a history of arteriosclerosis obliterans, chronic gastritis, hiatal hernia, and constipation. She was asymptomatic at presentation. Her height was $147 \mathrm{~cm}$, and her weight was $41 \mathrm{~kg}$. Her
STS (the Society of Thoracic Surgery) score was 3.472\%; Clinical Frailty Score was 4. TTE revealed a left ventricular (LV) ejection fraction of $68 \%$, an aortic valve peak velocity of $4.3 \mathrm{~m} / \mathrm{s}$, a mean gradient of $47 \mathrm{mmHg}$, and an aortic valve area of $0.65 \mathrm{~cm}^{2}$. Electrocardiogram (ECG)-gated computed tomography revealed that the aortic valve area was $392 \mathrm{~mm}^{2}$, the circumference of the aortic valve was $72.4 \mathrm{~mm}$, and the major and minor diameters of the aortic valve were 24.1 and $19.2 \mathrm{~mm}$, respectively. The height of the valsalva sinus was $\geq 15 \mathrm{~mm}$, and the diameter of the valsalva sinus was $\geq 29 \mathrm{~mm}$. Because the femoral artery and aorta were deemed adequate for a femoral artery approach, we planned to implant an Evolut R 29-mm valve (Medtronic, Minneapolis, Minnesota, US) via the transfemoral approach.

TEE probe insertion was not suitable because of the hiatal hernia; therefore, the patient underwent LA and laryngeal mask airway intubation, and TAVR was performed under ICE guidance. There were two puncture sites of the patient, one was a 6-Fr 10-cm sheath (Radifocus Introducer II H; Terumo, Tokyo, Japan) which was inserted from the right internal JV as a temporary pacemaker, and the other was a $14-\mathrm{Fr} 10-\mathrm{cm}$ sheath (Arrow Multi-Lumen Access Catheter; Teleflex, Pennsylvania, US) which was inserted from the cranial side for the ICE catheter insertion and inotrope drip (Figure 1,S1,S2). ICE was performed with an 8-Fr AcuNav ${ }^{\mathrm{TM}}$ catheter (Siemens, Erlangen, Germany) with imaging on a Vivid Q ultrasound laptop (GE Healthcare, Buckinghamshire, UK), advanced from the right internal JV to the superior vena cava.

On advancing the catheter by about $5 \mathrm{~cm}$ with counterclockwise rotation, the ascending aorta was obtained (Figure 2,S3). The ascending aorta was evaluated prior to the procedure. The atrial septum was obtained on advancing the catheter by a few $\mathrm{cm}$ (Figure 3,S4). There was no atrial septal defect or patent foramen ovale. With clockwise rotation, a long-axis view of the right atrium, tricuspid valve, and right ventricle was obtained. Preoperative tricuspid regurgitation and estimated right ventricular systolic pressure (RVSP) were measured (Figure 4A,B,S5). Pushing forward for the right ventricle with anterior flexion and counterclockwise rotation, a longaxis view of the left ventricle was obtained (Figure $5 A, S 6$ ). Before the procedure, this view showed LV contraction and pericardial effusion, and during the procedure, it showed the position of the wire (Figure $5 B$ ). When the catheter was returned in the clockwise direction and pulled to the right atrium, a long-axis view of the aortic valve was obtained 


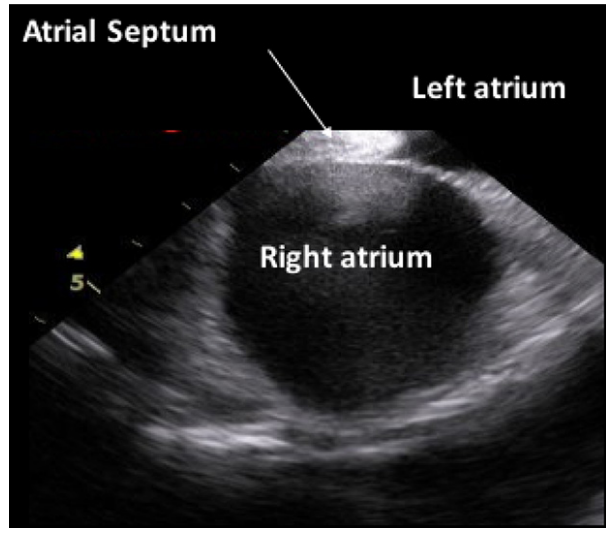

Figure 3 Atrial septum view: this view may be less useful during transcatheter aortic valve replacement (TAVR) but may be useful during interventions for other structural heart diseases that require the Brockenbrough method.
(Figure $6 A$ ). In this view, the preprocedural aortic valve flow velocity was measured (Figure $6 B$ ). The diameter of the aortic valve complex was measured (Figure 6C). After implantation of the valve, mild-to-moderate paravalvular aortic regurgitation from the edge of the non-coronary cusp was observed (Figure 6D,S7). However, due to the appearance of an atrioventricular block, we did not perform post-dilatation.

Finally, we evaluated the changes in pericardial effusion, LV wall motion, RVSP, mitral valve regurgitation, postoperative aortic valve flow velocity, and ascending aortic aorta. The ICE catheter was removed, and the patient was transferred to the intensive care unit with two in situ sheaths and a temporary pacemaker.

The operation time was 55 minutes, and the anesthesia time was 124 minutes. The volume of the contrast agent used
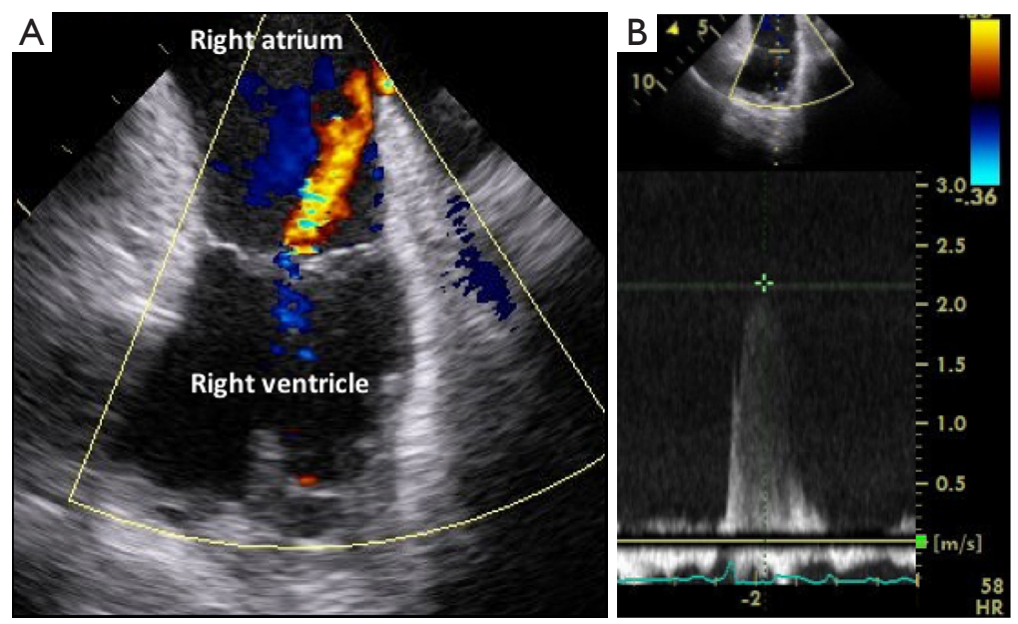

Figure 4 Long-axis tricuspid view. (A) There was mild tricuspid regurgitation; (B) the tricuspid regurgitation pressure gradient was 18 $\mathrm{mmHg} ; 4 \mathrm{mmHg}$ of the central venous pressure was added, and the estimated right systolic ventricular pressure was $22 \mathrm{mmHg}$.
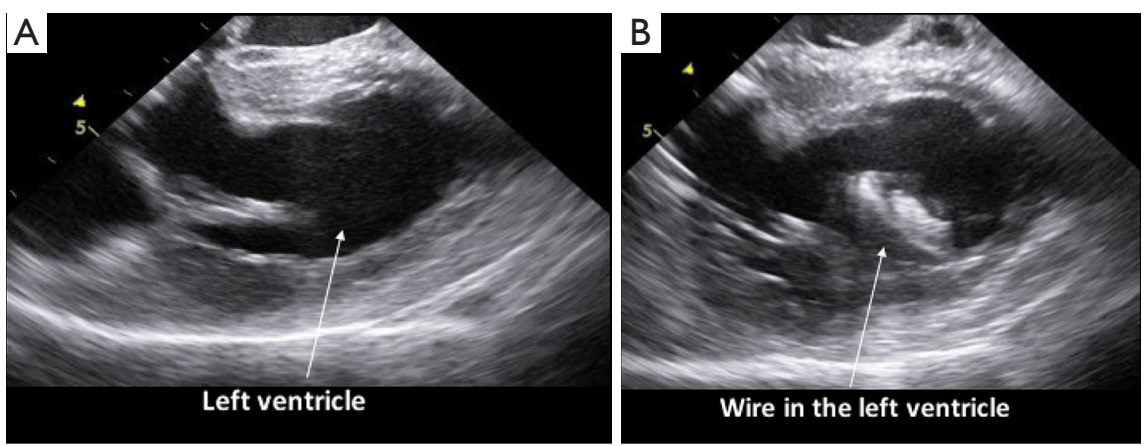

Figure 5 Long-axis left ventricular view. (A) There was no left ventricular wall motion synergy or signs of pericardial effusion; (B) we could confirm the position of the wire during the procedure. 


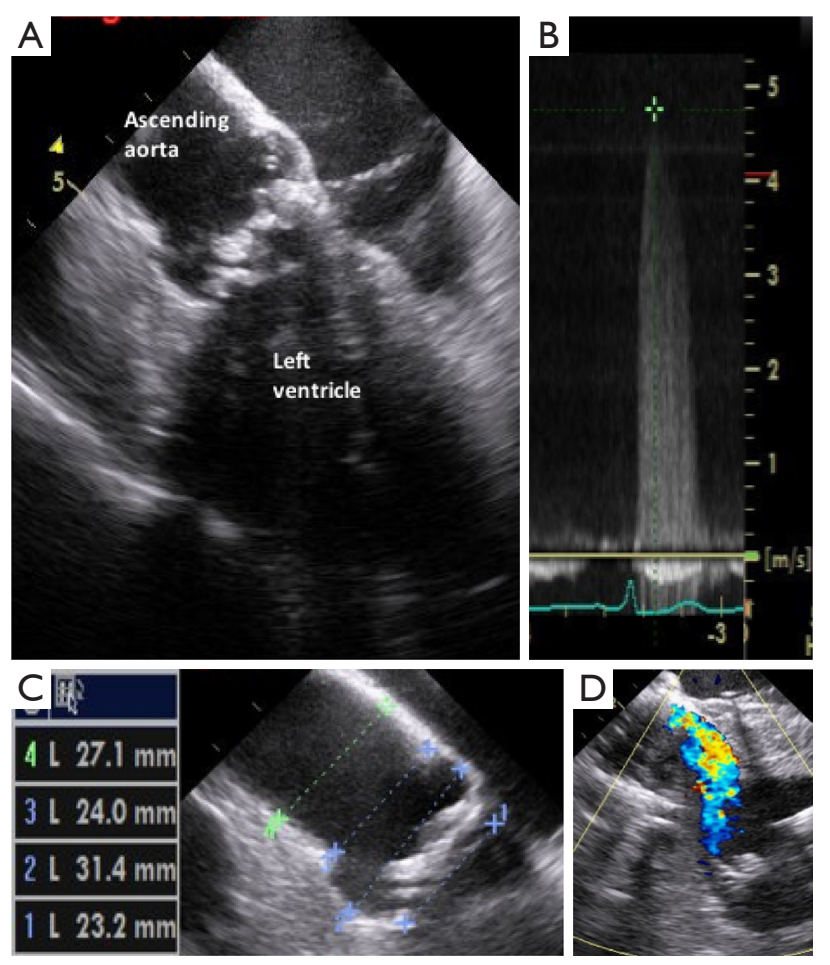

Figure 6 Long-axis aortic valve view. (A) A view akin to the $135^{\circ}$ view during transesophageal echocardiography (TEE) was obtained; (B) the aortic valve flow velocity as measured by jugular vein-intracardiac echocardiography (JV-ICE) was $4.75 \mathrm{~m} / \mathrm{s}$. It is typically difficult to measure the flow velocity with TEE; however, JV-ICE was able to measure it for straight; (C) the basal ring was $23.3 \mathrm{~mm}$, the valsalva sinus was $31.4 \mathrm{~mm}$, the sinotubular junction diameter was $24.0 \mathrm{~mm}$, and the ascending aorta diameter was $27.1 \mathrm{~mm}$; (D) there was mild-to-moderate paravalvular aortic regurgitation from the edge of the non-coronary cusp.

was $60 \mathrm{~mL}$, and the fluoroscopy time was 16.1 minutes. The heart rhythm improved from pacing rhythm to sinus rhythm on the first postoperative day; therefore, the temporary pacemaker was removed on the second postoperative day. Subsequently, she developed a urinary tract infection and underwent antibiotic therapy. She was finally discharged on the $15^{\text {th }}$ postoperative day.

\section{Discussion}

This is the first documented case of TAVR performed under LA with JV-ICE. Using JV-ICE, we were able to obtain the following five views akin to those obtained with TEE: long-axis ascending aorta view, atrial septum view, long-axis tricuspid view, long-axis LV view, and long-axis aortic valve view.

As imaging modality of echocardiography, there are four procedures; TTE, TEE, FV-ICE, and JV-ICE.

\section{$\mathcal{F}$-ICE vs. TEE}

It was easy to evaluate the ascending aorta with JV-ICE, which is typically difficult to evaluate with TEE. The accurate evaluation of RVSP and aortic valve flow velocity is also difficult with TEE; however, it is relatively easy with JV-ICE because tricuspid regurgitation and aortic valve flow velocity can be obtained. Although we did not compare with TEE in this case, we could measure the aortic valve complex with JV-ICE in a view that was akin to that obtained with TEE. Therefore, JV-ICE allows for the evaluation of perioperative hemodynamics, measurement of the aortic valve complex, and assessment of major complications during the procedure.

\section{FV-ICE vs. TTE and FV-ICE}

For JV-ICE, there is no need for the echocardiologist to be clean, and the operator can perform the procedure in the standing position akin to that with TEE; lastly, JV-ICE offers greater operability than that with FV-ICE. All these points indicate the superiority of JV-ICE over FV-ICE.

\section{FV-ICE vs. TTE, TEE, and FV-ICE}

JV-ICE can obtain images without interference from the operator or the fluoroscope, which represents a distinct advantage over TEE, TTE, and FV-ICE.

There are four limitations of JV-ICE. First, during insertion of the ICE catheter from the right internal JV, it is necessary to insert three sheaths for (one each for the pacemaker, central venous catheter for inotrope, and ICE). To minimize the number of punctures, we used a $14-\mathrm{Fr}$ sheath with a central venous catheter combined with ICE lumen in this case; however, this led to an increase in the thickness of the sheath. Second, the ICE catheter may interfere with the pacemaker, although this can also occur with FV-ICE. Third, there is a possibility of injury to the heart and vessels, and the risk of arrhythmia is higher than that with TEE and TTE. Fourth, the resolution afforded by JV-ICE is lower than that with TEE; therefore, there is a possibility of underestimating the complications and changes, particularly paravalvular aortic valve regurgitation. 
In the case of LA, there were only options to perform with FV-ICE, TTE or without echocardiography. However, JV-ICE offers the above advantages over these procedures, and TAVR with JV-ICE may potentially minimize the complications of TAVR under LA and improve patient prognosis.

\section{Conclusions}

The use of JV-ICE allows the operator and echocardiologist to perform without interference from each other, and it is possible to depict the image without overlapping with the fluoroscopic apparatus. JV-ICE is a promising alternative to TEE, TTE, or FV-ICE for TAVR performed under LA.

\section{Acknowledgements}

None.

\section{Footnote}

Conflicts of Interest: The authors have no conflicts of interest to declare.

Informed Consent: Written informed consent was obtained from the patient for publication of this manuscript and any accompanying images.

\section{References}

1. Baumgartner H, Falk V, Bax JJ, et al. 2017 ESC/EACTS Guidelines for the management of valvular heart disease. Eur Heart J 2017;38:2739-91.

2. Nishimura RA, Otto CM, Bonow RO, et al. 2014 AHA/ ACC guideline for the management of patients with valvular heart disease: a report of the American College of

Cite this article as: Yagasaki H, Goto Y, Mori Y, Noda T. Transcatheter aortic valve replacement with intracardiac echocardiography from the right internal jugular vein. Cardiovasc Diagn Ther 2018;8(4):525-529. doi: 10.21037/ cdt.2018.07.06
Cardiology/American Heart Association Task Force on Practice Guidelines. J Am Coll Cardiol 2014;63:e57-185.

3. Bufton KA, Augoustides JG, Cobey FC. Anesthesia for transfemoral aortic valve replacement in North America and Europe. J Cardiothorac Vasc Anesth 2013;27:46-9.

4. Di Mario C, Eltchaninoff H, Moat N, et al. The 2011-12 pilot European Sentinel Registry of Transcatheter Aortic Valve Implantation: in-hospital results in 4,571 patients. EuroIntervention 2013;8:1362-71.

5. Auffret V, Lefevre T, Van Belle E, et al. Temporal Trends in Transcatheter Aortic Valve Replacement in France: FRANCE 2 to FRANCE TAVI. J Am Coll Cardiol 2017;70:42-55.

6. Yamamoto M, Meguro K, Mouillet G, et al. Effect of local anesthetic management with conscious sedation in patients undergoing transcatheter aortic valve implantation. Am J Cardiol 2013;111:94-9.

7. Ehret C, Rossaint R, Foldenauer AC, et al. Is local anaesthesia a favourable approach for transcatheter aortic valve implantation? A systematic review and metaanalysis comparing local and general anaesthesia. BMJ Open 22017;7:e016321.

8. Bartel T, Bonaros N, Müller L, et al. Intracardiac echocardiography: a new guiding tool for transcatheter aortic valve replacement. J Am Soc Echocardiogr 2011;24:966-75.

9. Kadakia MB, Silvestry FE, Herrmann HC. Intracardiac echocardiography-guided transcatheter aortic valve replacement. Catheter Cardiovasc Interv 2015;85:497-501.

10. Bartel T, Müller S, Biviano A, et al. Why is intracardiac echocardiography helpful? Benefits, costs, and how to learn. Eur Heart J 2014;35:69-76.

11. Bartel T, Edris A, Velik-Salchner C, et al. Intracardiac echocardiography for guidance of transcatheter aortic valve implantation under monitored sedation: a solution to a dilemma? Eur Heart J Cardiovasc Imaging 2016;17:1-8. 


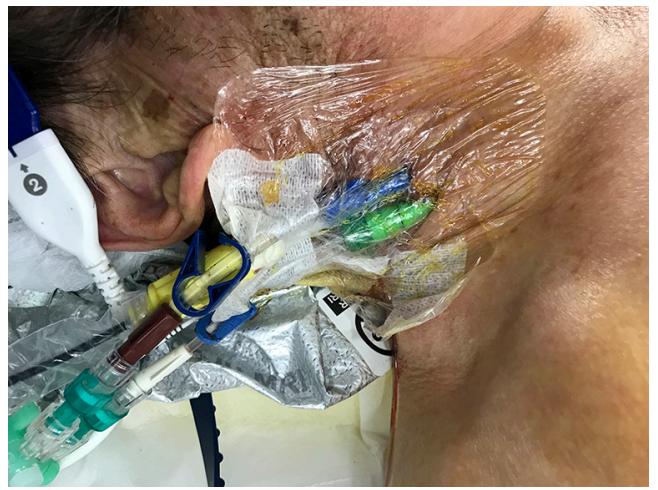

Figure S1 Image of the right jugular venous access with sheath, temporary pacemaker wire and ICE catheter of another patient. ICE, intracardiac echocardiography.

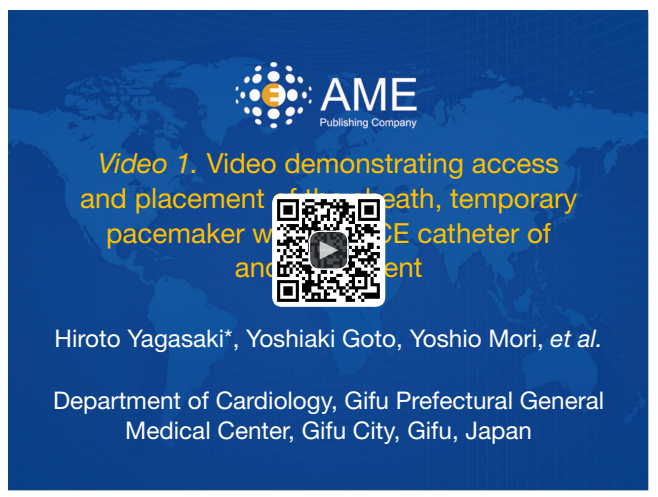

Figure S2 Video demonstrating access and placement of the sheath, temporary pacemaker wire and ICE catheter of another patient (12). ICE, intracardiac echocardiography.

Available online: http://www.asvide.com/article/view/26386

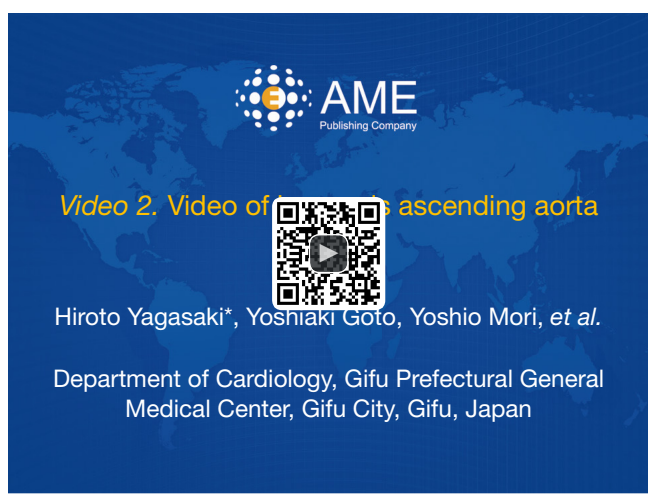

Figure S3 Video of long-axis ascending aorta view (Figure 2) (13). Available online: http://www.asvide.com/article/view/26387

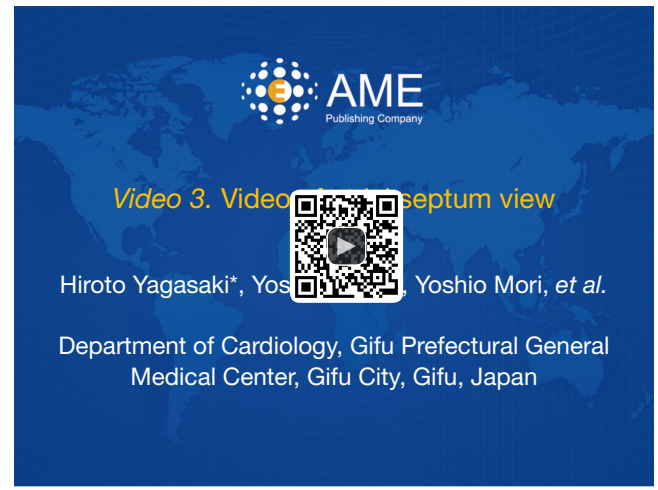

Figure S4 Video of atrial septum view (Figure 3) (14). Available online: http://www.asvide.com/article/view/26388

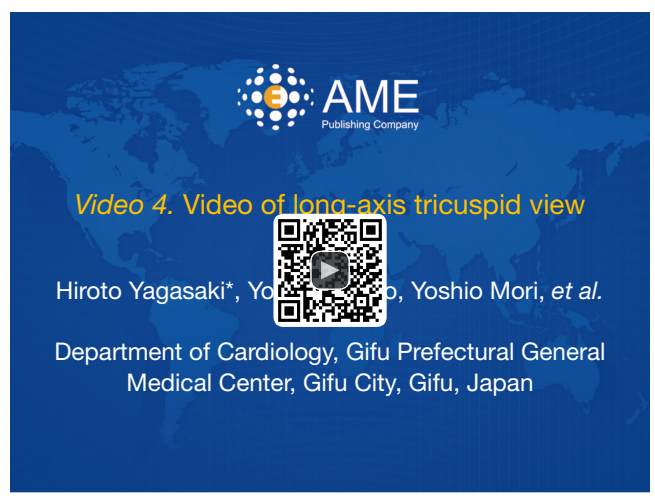

Figure S5 Video of long-axis tricuspid view (Figure 4) (15). Available online: http://www.asvide.com/article/view/26389

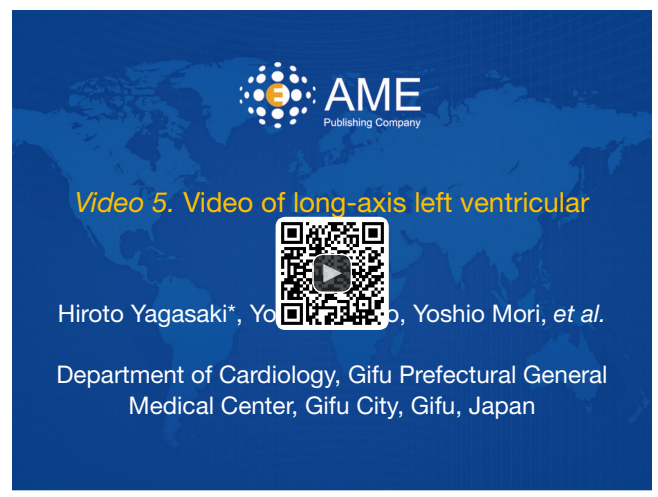

Figure S6 Video of long-axis left ventricular view (Figure 5) (16). Available online: http://www.asvide.com/article/view/26390 


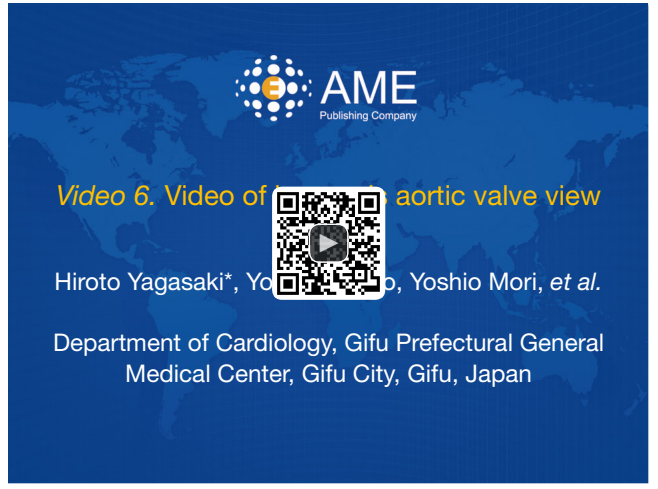

Figure S7 Video of long-axis aortic valve view (Figure 6) (17). Available online: http://www.asvide.com/article/view/26391

\section{References}

12. Yagasaki H, Goto Y, Mori Y, et al. Video demonstrating access and placement of the sheath, temporary pacemaker wire and ICE catheter of another patient. Asvide 2018;5:680. Available http://www.asvide.com/article/ view/26386

13. Yagasaki H, Goto Y, Mori Y, et al. Video of long-axis ascending aorta view. Asvide 2018;5:681. Available online: http://www.asvide.com/article/view/26387

14. Yagasaki H, Goto Y, Mori Y, et al. Video of atrial septum view. Asvide 2018;5:682. Available online: http://www. asvide.com/article/view/26388

15. Yagasaki H, Goto Y, Mori Y, et al. Video of long-axis tricuspid view. Asvide 2018;5:683. Available online: http:// www.asvide.com/article/view/26389

16. Yagasaki H, Goto Y, Mori Y, et al. Video of long-axis left ventricular view. Asvide 2018;5;684. Available online: http://www.asvide.com/article/view/26390

17. Yagasaki H, Goto Y, Mori Y, et al. Video of long-axis aortic valve view. Asvide 2018;5:685. Available online: http:// www.asvide.com/article/view/26391 